\title{
La santería cubana en Venezuela, nuevo campo de acción para la pastoral"
}

\author{
Edixsandro de Jesús Morán Soto ${ }^{* *}$
}

Recibido: 29 de septiembre 2014 • Aprobado: 28 de noviembre 2014

\section{Resumen}

Este artículo muestra de manera general la práctica de la santería en Venezuela, que hunde sus raíces en su anterior vida en África, que se extiende en sus ramas hasta Cuba con la llegada de los esclavos a esta tierra, y que en la última década hace nido en tierras venezolanas. Su influencia se deja ver sobre todo en gran parte de la población de los fieles católicos, quienes no logran distinguir prácticas de devoción popular con los ritos de santería; de los simpatizantes del gobierno chavista, quienes la han popularizado como la "religión de pueblo bolivariano", en sintonía con las ideologías nacionalista del actual gobierno de Venezuela y, por supuesto, de las nuevas generaciones de los nacidos en el seno de estas comunidades santeras.

Aquí señalamos también el fenómeno del auge de la santería en Venezuela en esta última década, con la llegada de médicos, profesores e ingenieros cubanos traídos a colaborar en la República Bolivariana en sus respectivas áreas, cargando consigo sus tradiciones y costumbres. Se introduce a nociones básicas de esta corriente como son: la Regla de Ocha, santería, los elementos del culto santero, sus ministros, sus divinidades "orichas", sus principales festividades, para terminar con la presentación de lo que la Iglesia católica define como religiosidad popular, que es expresión de fe de un pueblo.

Palabras clave: santería, religiosidad popular, sincretismo, culto cristianismo, pastoral.

* Texto producto de las investigaciones del autor.

** Teólogo de la Universidad Santo Tomás en Colombia. Fraile dominico de la Provincia de Venezuela. Correo electrónico: frayedixmor@gmail.com 


\title{
Cuban santeria in Venezuela, new field of action for pastoral
}

\begin{abstract}
:
This article shows in a general way the practice of the santeria in Venezuela, which sinks his roots in the previous life in Africa, which spreads in theirs branches up to Cuba with the arrival of the slaves to this land, and which in the last decade does nest in Venezuelan lands. His influence it is possible to estimate this in a great number of the catholic faithfulness, for they do not manage to distinguish between the practices of popular devotion and the rites of santeria; of the sympathizers with the chavista government, those who have popularized it as the "the religion of bolivarian people " in tuning in with the ideologies nationalist of the current government of Venezuela, and certainly, of the new generations of born in the bosom of these santeras communities.

Here distinguishes itself also the phenomenon of the summit of the holiness in Venezuela in the last decade, with the arrival of doctors, teachers and Cuban engineers brought to being employed at the Republic Bolivarian in their respective areas, loading with they the traditions and customs. It interferes to basic notions of this current since they are: Ocha's Rule, santeria, the elements of the santeria worship, their ministries, their divinities "orishas", and their principal celebrations, to end with the presentation of what the Catholic Church defines as a popular religiousness, which is an expression of faith of a people.
\end{abstract}

Keywords: Santeria, popular religiosity, syncretism, rituals, pastoral.

\section{La santeria cubaine au Venezuela, nouveau champ d'action pour la pastorale}

\section{Résumé}

Cet article montre de manière générale, la pratique de la Santeria au Venezuela, dont ses racines pénètrent ses vies antérieures en Afrique, dont ses branches se prolongent jusqu'à Cuba avec l'arrivé des esclaves sur cette terre, et qui durant la dernière décennie fait son nid en territoire vénézuélien. Son influence est visible surtout en grande partie au sein de la population des fidèles catholiques, lesquels n'arrivent pas à faire la différence entre les pratiques de dévotion populaire et les rites de Santeria; des sympathisants du gouvernement chaviste, qui l' ont rendu populaire en tant que «religion du peuple bolivarien ", en syntonie avec les idéologies nationalistes du gouvernement vénézuéliens actuel et bien entendu, des nouvelles générations nées au sein de ces communautés adeptes à la santeria. 
Nous signalons également ici, le phénomène de l'essor de la santeria au Venezuela durant la dernière décennie, avec l'arrivée de médecins, professeurs et ingénieurs cubains, amenés pour collaborer avec la République Bolivarienne dans ses différents domaines, perpétuant leurs traditions et coutumes. Ils introduisent les notions basiques de ce courant tels que: La Règle de Ocha, santeria, les éléments du culte de la santeria, ses ministres, ses divinités «orichas» ses principales festivités, pour terminer avec la présentation de la religion populaire définie par l'église catholique, expression de foi d'un peuple.

Mots clé: Santeria, religiosité populaire, syncrétisme, culte Chrétien, pastoral.

\section{Una pasajera clandestina llega a América}

Cuando nos detenemos a pensar en el proceso de colonización, inmediatamente nuestra mente es invadida por las imágenes de grandes barcos de madera, de europeos vestidos con trajes decorosos, de indios casi desnudos, de negros, de esclavitud, de guerras y todo cuanto la fantasía asocia a los datos históricos, nos permita volar. Pero, quién imaginaría que en estos barcos, además de transportar negros, llegaban también en la clandestinidad las divinidades del continente africano, que encontraron en suelo americano su nuevo panteón.

¿Cómo sucedió esto? Es importante esclarecer esta pregunta clave para la comprensión de todo este fenómeno que se conocería en un futuro no muy lejano como santería, contando a partir de la llegada de los esclavos africanos al nuevo continente, y en especial a la Isla de Cuba, lugar de origen de esta nueva práctica espiritual.

A partir de la defensa del trato a los indios, de su dignidad, de reconocerlos como personas a partir de Real Cédula expedida por los reyes de España en 1545, se abandonó en gran escala la mano de obra en el campo por parte de los indios y se convirtió en la herencia de los negros esclavos, quienes trabajarían en las fincas de café, de caña y de azúcar, las cuales se encontraban lejos de toda población urbana, en aquella época. Esto fue por supuesto un ambiente preciso para que los africanos practicarán sus liturgias, entonaran sus cánticos a sus ancestrales divinidades con el acompañamiento del toque de tambores. Lejos de toda ciudad y de toda villa, los negros quedaron también fuera del radio de evangelización que se había trazado la Iglesia católica, siendo éste también un factor a favor de las prácticas religiosas africanas.

Por otro lado, para el año 1568 existen los cabildos de la nación o cabildos de negros, legalmente autorizados y que tendrían repercusiones en la nueva organización social y religiosa de los negros; lo cual contribuyó a mantener intacta la religión 
que los negros traían de su amada África. “Algunos de ellos, de estirpe real y procedentes de tribus con sensibilidades artísticas y estéticas, trasladaron esos conocimientos a descendientes y contemporáneos, que sirven hoy, a nuevas generaciones de cubanos, de inspiración inagotable." (Bolívar, 1995. Págs. 52-160). Todo esto será el trampolín, en el que rebotará la santería, hacia el futuro en tierras caribeñas.

\section{Principales manifestaciones religiosas, que llegan a Cuba desde África}

Como ya se ha dicho en el punto anterior, los negros fueron traídos para ser esclavos, pero con ellos también viajaba la libertad; puesto que de alguna manera prudente se opusieron a la colonización radical de los españoles, se resistieron, además, a ser arrancados por completo de sus raíces y trajeron consigo una porción de su tierra: sus creencias, su fe, sus cultos y sus ritos.

En el ejercicio de sus ritos era donde experimentaban la libertad, el abrazo de sus "orichas" y así el dolor se hacía más llevadero. ¿Quiénes son los orichas? Oricha es un vocablo yoruba que traducido al español de forma literal significa "protector de cabecera". Según la mitología yoruba los orichas son funcionarios del dios Odumare (dios supremo que siempre ha existido), para brindar sabios consejos, a través de la iluminación, a los humanos. Estos, se les conocerá como "santos", en la santería cuabana.

Es menester aclarar aquí que fueron diversas las prácticas religiosas africanas que viajaron hasta tierras latinas con los negros. Nos ocuparemos de las dos ramas principales que influyeron en el proceso de sincretización, que deviene en la santería; a saber: la Regla de Ocha y de la Regla de Palo Monte.

\section{La regla de Ocha}

Ochá-orisha traduce "santo", "deidad". Una de las más grandes etnias traídas a Cuba, fue la etnia yoruba procedentes de Nigeria y que durante mucho tiempo de la historia, llegaron a ser un gran reino. Muchos arqueólogos concuerdan que habitan a lo largo del río Níger desde la prehistoria. ¿Quiénes son los yorubas y cuál es su origen? Para responder a estas preguntas, podemos encontrar dentro de las tradiciones yorubas un relato mítico sobre su origen. Este relato reseña así:

La teología Ifa plantea que la creación de la humanidad aconteció en la sagrada ciudad de Ile-Ife, donde Oduduwa creó tierra firme del agua. 
Mucho tiempo después un número desconocido migró hacia Ile Ife. En este punto se sinergizaron los africanos orientales y occidentales. Algunas hipótesis, basadas en la similitud de las esculturas egipcias y las encontradas en la ciudad estado de Ife, señalan que los Yorubas pueden descender de los Oduduwa provenientes de Egipto y que estos fundaron los primeros reinos.

Los Yorubas aún se denominan a sí mismos "Los hijos de Oduduwa". (Muñoz, 2006, p. 2).

En Cuba, la mitología yoruba dice que el panteón de sus divinidades ha permanecido intacto, junto al complejo litúrgico con el que dan culto a sus deidades. No ocurre así en el continente africano de donde proviene ahora perdieron su núcleo original al fusionarse con otras creencias propias de las tribus que hacen vida en este continente. Miremos su mitología tal y como se cuenta hoy en día en América:

Al principio de los tiempos fueron separados Orún y Aiye. Orún el mundo metafísico donde habitan los dioses orishas. Aiye el mundo físico del hombre. Algún día, en el fin de los tiempos, Orún y Aiye se unirán y formarán el infinito real en que dioses y hombres convivirán por siempre. Odumare supremo dios omnipotente siempre existió. Se aburrió de estar solo en el universo. Creó a Orún para que vivieran los dioses y a Aiye para que vivieran los hombres. En Orún hizo la morada de los Ancestros o Bazimus. Luego creo a Obatalá el primer hombre mortal, a Odudúa la primera mujer mortal y a Omo-Oba el primer hombre inmortal. Omo-Oba pecó de soberbia y su padre lo persiguió con rayos y centellas para matarlo. Omo-Oba huyó y se escondió en el centro de la Tierra; todavía sus suspiros producen las erupciones de los volcanes; algunas veces sale a predicar a los hombres desobediencia a Odumare y los orishas. Obatalá y Odudúa se casaron y tuvieron por hijos a Aganyú y Yemayá. Aganyú y Yemayá se casaron y de sus unión solo nació Orungán. Cuando murió Aganyú y Orungán fue hombre violó y fecundó a su madre Yemayá. Yemayá estuvo muerta siete días y de sus huesos nacieron Obafulom e Iyáa, procreadores de todo el género humano. Yemayá resucitó después de siete días y dio a luz a catorce hijos. Yemayá se convirtió en diosa de las aguas. Yemayá se convirtió en madre de todos los dioses y madre de todos los hombres. Sus catorce hijos se repartieron el universo y se llamaron orichas o vudús. Aye-Shaluga es el oricha 
de la fortuna y se le representa con una concha de mar. Babalú-Ayé es el oricha que produce y cura las enfermedades, es un anciano leproso acompañado de dos perros. Changó es el oricha de la guerra, la fecundidad, la danza, dueño de los tambores, símbolo del rayo y del tambor rojo, protector de rayos, centellas y tormentas. Chankpala es un oricha terrible, causa las enfermedades producidas por la picada de insectos. $D a d a$ es el oricha de la siembra. Oba es la diosa del río. Oba, es hermana y esposa de Changó. Ochosí es el protector de los cazadores y animales salvajes. Ochú es la diosa Luna. Orún es el dios Sol. Oke es el oricha de las montañas y protector de quienes habitan en sus cimas. Olokún es el dios de las profundidades marinas y está rodeado de hombres, peces y sirenas con quienes copula, su madre lo parió hermafrodita. Olosa es la diosa protectora de los pescadores, su mensajero es su cocodrilo y es concubina de su hermano Changó. Oshún es la diosa del amor y del oro y es también concubina de su hermano Changó. Ya es la diosa de la justicia y fortalece la memoria tiene nueve cabezas y en su mano derecha porta una llave de donde Changó alimenta su fuego, su mensajero es Alefi el viento y es amante de su hermano Changó. Odumare creó otros orichas para que también se repartieran el universo. Chiyidi el oricha de las pesadillas. Elegúa El Poderoso, el inetermediario entre los vivos y los muertos y mensajero de los orichas, Ifá-fa el oricha del destino que esta grabadado en sus tablas sagradas, donde están escritos todos los destinos pasados, presentes y futuros de los hombres,los dioses y el universo, tiene dieciséis ojos cerrados que solo puede abrir Eleguá. El Poderoso Kongorioco es el oricha de las cosas ocultas y tiene el don de la adivinación. Ogún es el dios del hierro y del fuego. Orúnla es el poseedor de las tablas de Ifá-fa. Osachín es el oricha de los curanderos y su símbolo es un halcón posado en una rama y Oyé que es un gigante que sopla los vientos es el dios de las tormentas [...] (Carvajal, 1999, pp. 50-51).

Existe un proceso de unificación respecto a la comprensión de la Regla de Ocha. Es muy común entre las religiones africanas que cada oricha tenga su narración histórica diferente. Ochún, Yemayá, Orula, se mencionan de acuerdo a sus historias y sobre todo a las experiencias de vida de sus creyentes y devotos. Esta situación provocaba, que la religión de los yorubas se hiciera cada vez más divergente, y los practicantes o iniciados en estas prácticas, al cambiar su residencia -por mencionar un hecho-, debían asentarse de nuevo (rito de iniciación), siendo 
este el motivo que llevó a Lorenzo Samá, un consagrado a Ifá, a reflexionar sobre la dispersión y la falta de unidad en los cultos yorubas.

Lorenzo, quien se hizo compañero de una negra yoruba, traída a Cuba en la década de los ochenta, emprendieron la ardua tarea de "unificar en un solo cuerpo litúrgico a las culturas yorubas, al cual denominaron Regla de Ocha" (Bolívar, 1997, p.162).

\section{La regla de Palo-Monte}

Otro grupo de africanos traídos a Cuba fueron los bantúes, procedentes de Angola, una etnia fuerte y alta. Dentro de estos, el grupo más importante fueron los congo, nativos de la cuenca del río del mismo nombre. Los congo tenían como religión la llamada mayombe, que a diferencia de las regla de Ocha, la congo Palo Monte es más de corte mágico. Su nombre se debe a la utilización de palos, raíces y troncos del monte, para confeccionar prendas y atuendos para sus ceremonias litúrgicas.

“El vocablo mayombe designa, por un lado la región africana de los montes de cristal, situados en la parte occidental que va de Gabón al norte de Angola y es atravesada por la cuenca del río Congo" (Rodríguez, 2012. pp. 53-54), pero por otro lado "es un vocablo congo que significa magistrado, jefe superior, gobernador, denominación o título honorífico" (Rodríguez, 2012. pp. 53-54). De aquí que el sacerdote de la religión mayombe se lo conozca como "mayombero", o "palero", es decir, hechicero que rinde culto a los muertos y a los espíritus de la naturaleza.

“Esta regla tiene más carácter mágico que la santería, pues en sus creencias el palero piensa que manipula las fuerzas naturales, otorgando una atención principal a los muertos ya que los invoca y los envía para que realicen sus trabajos" (Rodríguez, 2012. p. 54).

Respecto a la mitología de Palo-Monte podemos decir que al igual que los yorubas los mayombes tienen su panteón divino. Para los "paleros" existe un dios supremo, fuerza máxima creadora del Universo, a la que llaman Tata Nzambi o Nzambia, del cual emana la fuerza de los mpungos o fuerzas mágicas.

Estos mpungos únicamente son "fuerzas", seres incorpóreos que nunca devienen en antropomórficos como los orichas, santos o vudús, aunque en Cuba por la influencia de la Regla de Ocha o Santería, se les sincretiza con los orichas y los santos del panteón católico.

Mientras que en el acto de posesión el oricha toma el control de todo el cuerpo del creyente, el mpungo o fuerza conga solo lo hace de la nuca y cabeza de su 
devoto, de ahí el nombre de caballo brujo que popularmente se le da al que cae en trance en la Regla de Palo Monte.

Los principales mpungos son:

Remolino Cuatro vientos. La fuerza benéfica del viento. Viento Malo, La fuerza maléfica del viento. Lucero mundo, fuerza benéfica del viento que recorre los caminos; Sarabanda son Briyumba, Fuerza del fuego y de los metales; Sebangandó, fuerza de los animales y el orden; Obayende, fuerza de las enfermedades; Kenké, fuerza de la vegetación; Gurufinda, fuerza de la paz y la concordia; Ntala-Nsamba, fuerza de los gemelos. Siete Rayos - Punto Firme, fuerza del Rayo; Madre Agua, fuerza del agua y de la maternidad; Chola Unwemwe, fuerza de las riquezas y del amor carnal; Centella Ndoke fuerza de la muerte. (Camargo, 2012, p. 1).

\section{El proceso de sincretización entre las religiones afrocubanas y el catolicismo:}

El sincretismo ocurre cuando varios rasgos culturales, de origen distintos se funden entre sí, dando como resultado la creación de uno nuevo. ¿Cómo fue el proceso de sincretización, que dejó como resultado la santería?

Andrés Petit, hombre culto, inteligente, terciario de la orden franciscana del convento de Guanabacoa era, además, indiobón ("jefe principal") de Isue de Bokokó en la sociedad secreta Abakuá (sociedad secreta integrada exclusivamente por hombres, traída a Cuba por los esclavos procedentes de Nigeria) unifica todas las manifestaciones en estos sistemas religiosos, tanto de origen africano como católico por él conocidas, tratando de lograr, con esto, el más alto grado de espiritualidad posible dentro de la indisoluble ética de blancos y negros. Sintetizó las Reglas de Palo, en la Regla Kimbisa y mezcló la mayombería (originario del Congo y Angola), la santería y el espiritismo... así como los santos de la Iglesia católica. Estos a su vez se imbrican en las creencias africanas con un folklórico surrealismo tropical, en sus leyendas o relatos, identificados con los de las vírgenes y los mártires [...] (Bolívar, 1997, p. 161). 


\section{La santeria, sincretismo y religión cubana}

"La santería es una religión cubana que mezcla las creencias yoruba africanas con el cristianismo católico" (Wilkinson, 2008, p. 285). Para entender este fenómeno en Venezuela, hay que tener presente que:

Este fenómeno ocurre cuando los credos o cultos de dos o más religiones o tradiciones religiosas se entremezclan. Así pasó en Cuba con las diversas expresiones religiosas africanas traídas a Cuba por los esclavos de aquel continente. Éstas se mezclaron y se fundieron entre sí y recibieron un influjo del catolicismo, que era la religión de los españoles y sus descendientes criollos, marcando ellas a su vez la religiosidad popular católica con creencias y ritos. (Rodríguez, 2012, p. 19).

De esta manera, la santería, se puede acusar como el resultado del cruce entre las religiones africanas y el cristianismo católico, que lleva el sello de "Made in Cuba"; porque sin duda, la santería es nacida en Cuba, allí encontró su piso. En la Isla caribeña, el folklor africano y surrealismo tropical- caribeño, se imbrican y dan paso a nuevas leyendas o relatos y comienza básicamente, de los elementos, de la cultura y de las tradiciones yorubas.

\section{El panteón celestial de la santería afrocubana}

El proceso de sincretismo se va dando a la par con el proceso de colonización y el de esclavitud. Los españoles imponen a los negros el catolicismo, por la fuerza y el uso de las armas, a lo que los negros esclavos no pusieron ni la menor resistencia.

Frente a la actitud esclavizante de los españoles y con una religión impuesta, los esclavos pronto comenzaron a relacionar a sus deidades con los santos católicos, según las características de cada uno; en otras palabras, por ejemplo, los esclavos comenzaron a notar cómo los católicos invocaban a Santa Bárbara, ante el trueno y la tempestad, muy similar a los atributos que los yorubas daban a su deidad, Changó, dios del fuego y del trueno.

Evidencias de esto se encuentran en el Sacro museo de Caracas, donde se puede encontrar una imagen de vestir de algún santo católico, con una piedrita tallada, con la imagen de una deidad yoruba, debajo del vestido. Así cuando los negros eran obligados a participar en las procesiones de los santos o de la Virgen, daba la impresión que los esclavos participan en los cultos católicos, pero lo que allí estaba sucediendo en realidad, era que brindaban culto a sus ocultas deidades 
y lo hacían con el toque de tambores, alaridos y danzas autóctonas de su eterna tierra África. Así fue como en la diáspora yoruba se fue originando este sincretismo, quedando relacionados los orichas con los santos y con la Virgen María, en sus diferentes advocaciones.

Por eso vemos que por sus características, por sus vestimentas y por su patronazgo, quedan relacionados con los orichas, generándose el panteón de la santería. Aquí se enlistan de forma resumida las asociaciones de santos, virgen y orichas:

Agayu, es San Cristóbal; Aguena, Santa Filomena; Babalu-aye, San Lázaro; Shango, Santa bárbara; Dada (obañeñe), podía ser San Ramón Nonato o nuestra Señora del Rosario; Eledda sería el ángel de la guarda; Elefuro, La Virgen del Carmen; Elegua- Eshu, por sus características de vestimenta o presentación podía ser el ánima sola, San Antonio de Padua, San Benito de Palermo o el santo Niño de Atocha; Elle cosun sería Santa lucía; Ibeyis o jimaguas, San Cosme y San Damián; Igui, San Lucas; Inle, San Rafael y San Roque; Iroko, La Purísima Concepción; Nana buruku, Santa Ana y la Virgen del Camino; Oba nani, Santa Catalina y Santa Rita de Casia; Obbatala, Las Mercedes, San José obrero, Jesús crucificado, Santa lucía, San Joaquín, Santa Eduvigis, y el Santísimo Sacramento; Obba moro, Jesús nazareno; Oduduwa, El Santísimo Sacramento; Oshosi, San Norberto, San Humberto. Oshumare, San Bartolomé; Oshun, La Caridad del Cobre; Oggun, San Pedro, San Juan, San Pablo, San Jorge, Santiago apóstol, San Antonio abad; Oggun chibiriki, San Miguel Arcángel; Oke, San Roberto; Olofin, Jesucristo; Olodumare, Gran Poder de Dios; Olorun, Espíritu Santo; Olokun, La Virgen de Regla. Olosi, Satanás. Oguidai, San Bartolomé; Orisha oko, San Isidro labrador; Orula o Orunmila, San Francisco de Asís; Osain, San Antonio abad y San Silvestre; Oya, La Virgen de candelaria; Osagriñan, San José; Osun, San Juan Bautista; Inle, San Julián; Yemaya, La Virgen de Regla; Yewa, Nuestra Señora de los desamparados, nuestra Señora de Montserrat, Santa Clara de Asís y Santa Rosa de Lima. (Muñoz, 2006, p. 6).

\section{La santeria cubana en venezuela}

Tras la llegada de Fidel Castro al poder en 1959, un éxodo de refugiados y exiliados llegaron a Venezuela desde Cuba. Muchos médicos y profesores cubanos arrastraron consigo creencias y prácticas religiosas, cuyos orígenes procedían 
de África, además de la convicción que tenían que estos rituales son capaces de resolver problemas sentimentales y curar todo dolor. Algunos incluso creían que ofrecen protección contra la delincuencia que descaradamente azotará a Venezuela.

Con el gobierno de Chávez, el auge de las prácticas de la religión afrocubana comienza a tener más presencia en diversas regiones del país. Si bien es cierto que la santería no es un fenómeno reciente en este país bolivariano, sí podemos observar como en la última década se propaga en gran parte de la geografía venezolana. ¿Cuál es la causa de esta propagación? Un principal factor que podemos mencionar es la ideología de un sistema político-nacionalista que Chávez, que ondula como bandera de su gobierno.

Las campañas del presidente Chávez van a estar a favor de ver la santería como una religión y no como una secta, como una religión "criollita" propia del pueblo. Y pronto comenzaron a tener reconocimiento y acogida por diversos sectores del país, en especial aquellos que simpatizan con las ideologías del Presidente. Grupos de santeros se animaron a anunciar sus predicciones e influencias de magia en periódicos e Internet, otorgando así a la santería un alto estatus en popularidad y realización de este culto espiritual.

Actualmente cuentan -los santeros-, con una organización y más libertad en la celebración de sus cultos, gracias a las mencionadas campañas y ya no de forma clandestina, como tal vez ocurría quince años atrás. Tanto es esto, que ya es normal verlos en las calles del país, distinguiéndose por su vestir de blanco; pero además, se les puede ver orando a sus dioses mimetizados en santos católicos, en iglesias católicas de distintas ciudades, y también han establecido como norma de vida la humildad, hermandad y honestidad.

Esta creciente popularidad de la santería se evidencia en gran parte en el comercio. Una proliferación de tiendas en las que se venden pequeños animales que son sacrificados ritualmente. Los ritos de iniciación, adivinación y magia son conservados en las casas de los creyentes, y allí tienen lugar los rituales, ya que no cuentan con templos propios para su culto.

\section{El auge de la santería}

La santería está en auge, porque hay mucha gente, que cuando está necesitada de ayuda, recurre a fuerzas superiores o espirituales, en búsqueda de auxilio, para superar los problemas. Ya no es extraño ver a creyentes católicos, vestidos de blanco, que acuden a la iglesia católica para adorar a Obatalá -por ejemplo- madre de los dioses yorubas, que desde hace décadas es representado en la Virgen de Las 
Mercedes. Cabe mencionar que la Iglesia Católica en Venezuela objeta el culto, pero hace tiempo que abandonó sus esfuerzos por prohibirlo.

Algunos creyentes llegan al conocimiento profundo de la santería para obtener poderes curativos que creen les otorgan los dioses; todo esto a través de rituales como el sacrificio de animales o las ofrendas para limpiar el espíritu. Algunos pagan grandes sumas para convertirse en babalaos o sacerdotes. Otros prefieren las prácticas de "magia negra", incluidos aquellos conocidos como "paleros", que recolectan huesos en cementerios y como parte de un ritual sellan un pacto con un muerto, que según la creencia es mutuamente beneficioso para ambos. Algunos paleros ofrecen mucho dinero por una calavera -puesto que el cráneo humano es de gran poder esotérico- generando así políticas de negocios y de comercio esotérico.

\section{Un caso particular en Venezuela}

La santería, como hemos dicho, es una religión afrocubana, tiene su principio en Cuba, allí se gestó, encontró su cuna, creció y comenzó a difundirse por costas e islas caribeñas. Pero esta religión, producto del sincretismo generado por la fusión de las religiones africanas, que estuvieron presentes en la Isla en medio del populo negro, y el cristianismo católico, religión oficial de toda colonia española, adquirirá un aspecto específico en Venezuela. Esto se menciona en un artículo publicado en la revista Pensamiento Humanista:

En Venezuela ocurre un caso particular de sincretismo entre las religiones africanas, precolombinas y el cristianismo. En efecto, escribe Angélica Pollak-Elks: “El culto a María Lionza, autóctono de Venezuela ha integrado elementos indígenas, africanos y cristianos en el curso de su formación...; absorbiendo creencias y prácticas tradicionales de los campesinos criollos en general...; Es esencialmente utilitario. En las últimas décadas, ha padecido muchas influencias de la santería cubana y así ha sido "re-africanizado" con respecto a los ritos mágicos y la veneración de las "siete potencia africanas", las siete divinidades más importantes del panteón yoruba de Nigeria, sincretizadas con santos católicos después de su traslado a Cuba en el siglo pasado. Es importante decir que el culto a María Lionza es originalmente indígena, sin embargo, es adorada como Santa y sus ritos son estrictamente africanos. (Carvajal, 1999. p. 53).

El mito indígena sobre el origen de "la reina", -como la llaman sus seguidores- dice que "María Lionza era un princesa de la etnia jirajara que fue secuestrada 
por una serpiente que custodiaba una laguna; como castigo, la serpiente se infló hasta reventar y causó una inundación que acabó con todo el pueblo de Jirajara, y la princesa se convirtió en señora de la laguna y luego de toda la naturaleza". (Izard, 1999, p. 108).

Actualmente, el culto a María Lionza cuenta con más de 200 mil devotos en Venezuela, que cada año peregrinan a su centro de veneración en la montaña Sorte en el estado Yaracuy ubicado en la cordillera central del país bolivariano. En este lugar, según sus fieles, puso su morada la diosa para que le rindan culto con la danza y el tambor, herencia de la cultura africana, así como también con la quema de pólvora y ofrendas de frutas, para obtener su favor. Hoy en día hace parte de las cortes celestiales de los santeros, por lo que se la puede ver en los altares de santería y se la conoce como santa María Lionza. Así en Venezuela se añadirá a lo afro-cubano y católico, aspectos propiamente indígenas-precolombinos.

\section{La santería, una expresión de religiosidad popular del pueblo venezolano.}

Utilizamos aquí la palabra "expresión”, porque si bien es cierto que la santería es una nueva propuesta religiosa en relación al cristianismo, también hay que recordar que es producto del sincretismo, en la cual convergen valores, mitos, conjuntos de creencias y, elementos folklóricos y litúrgicos; de las religiones africanas y de las autóctonas, y del cristianismo. Sin embargo, en este proceso de mezcolanza, sin duda alguna los elementos que más sobre salen son los de aquella religión que tenga mayor organización, un código moral más definido y un andamiaje litúrgico perfectamente armado y universalmente extendido. Evidentemente en la santería prevalecerán los elementos católicos.

Por tanto, no es que los santeros vean al catolicismo con una religión distinta, muy por el contrario, la santería no se desvincula de la Iglesia católica y este hecho puede ser verificable en los mismos templos, cuando vemos a los santeros llevando ofrendas, celebrando algún obituario, es más, todos son bautizados en la Iglesia católica, asisten a novenas, van ante los sacerdotes católicos para que les bendiga el agua o les celebre algún funeral, en fin la santería se presenta en Venezuela, como un catolicismo popular en el que se le rinde culto a Cristo y veneración a la Virgen y a los santos, con nombres africanos pero que conservan sus atributos, tal cual, que en la Iglesia católica.

En consecuencia, la Iglesia católica en Venezuela, debe voltear su mirada a la santería, como un campo de evangelización y brindar orientación espiritual. 
Así lo expone el Papa Juan Pablo II, en su discurso a los obispos de Cuba en visita ad limina apostolorum en agosto de 1988: “La religiosidad popular, purificada en sus motivaciones ajenas al mensaje cristiano y fundamentada en la persona de Cristo, en el culto a la Virgen y a los santos, es un terreno muy propicio para la evangelización". (cf. DI, 1988. n 6).

Esta invitación que otrora, hiciera el Papa Juan Pablo II a los obispos de Cuba, también se ha hecho en reiteradas ocasiones a toda la Iglesia del continente de la esperanza, por parte del Magisterio, en su hacer reflexivo sobre, cómo debe estar la iglesia en latinoamérica y el Caribe.

De manera que, la reflexión teológica sobre la santería en Venezuela aparece como una necesidad a la que se deberá dar pronta respuesta desde la pastoral. Para los teólogos venezolanos sigue sin entrar en vigencia el llamado que hicieron los obispos en la asamblea de Medellín: “Que se realicen estudios serios y sistemáticos sobre la religiosidad popular y sus manifestaciones, sea en universidades católicas, sea en otros centros de investigación socio-religiosa". (cf. DM, n 10).

\section{Principales aportes del Magisterio de la Iglesia, para comprender la religiosidad popular}

El Concilio Vaticano II representa para la Iglesia, la puerta con la que se abre al mundo y a los signos de los tiempos, así como también el hecho de asumir su misión en el mundo como madre y maestra del género humano. Esta reflexión posibilitó que la Iglesia se replanteara sus relaciones con las otras denominaciones cristianas y también con las religiones no cristianas en la que se nos pide valorar todo aquello que tenga destello de santidad y de verdad en otras religiones (cf. NA.1965. ns 1s).

La expresión "religiosidad popular es utilizada por primera vez en la conferencia de Obispos de Latinoamérica que se celebró en esta ocasión en Puebla, México en 1979. Esta asamblea de obispos expuso su definición de religiosidad popular, llamándola, "la religión del pueblo", asegurando que es a través de esta, el pueblo continuamente se evangeliza a sí mismo, sin embargo advierten, los obispos latinoamericanos, que está religiosidad en la que se encuentra de forma activa la Palabra de Dios aún siguen sin permear las estelas religiosas africanas que guardan la "semilla del verbo" y que quedaron en medio de nuestros pueblos bajo la sombra del sincretismo. (cf. CP. ns 444-452).

Años más tarde, en el 2007 se vuelve a poner sobre el tapete el tema de la religiosidad popular. Se reúne -en Aparecida, Brasil- nuevamente la Conferencia 
Episcopal Latinoamericana, para tratar temas concernientes sobre la Iglesia en América Latina, y de entre los diversos tópicos tratados, el Santo Padre Benedicto XVI destacó la "rica y profunda religiosidad popular, en la cual aparece el alma de los pueblos latinoamericanos", y la presentó como "el precioso tesoro de la Iglesia católica en América Latina" (cf. CA. ns 252-253)

Por otro lado, en Ecclesia in America, la religiosidad popular es definida como "el lugar de encuentro con Cristo para todos aquellos que con espíritu de pobreza y humildad de corazón buscan sinceramente a Dios". Esta búsqueda sincera de Dios, prosigue la exhortación apostólica, debería ser enriquecido con la doctrina católica (cf. EA, ns 16-18)

Todos estos documentos del Magisterio, ponen de relieve la importancia que tienen las prácticas de devoción popular para la Iglesia y en concreto las surgidas de en medio del pueblo cristiano latinoamericano. Además, en los citados documentos se exponen líneas de acción pastoral para el dialogo, trato y cuidado del "catolicismo del pueblo".

En tal sentido, podemos a definir la religiosidad popular, a como una expresión espontánea de las personas al manifestar su fe, involucrando en este proceso todas sus dimensiones (artísticas, psicológicas, social, político, económico) para generar un puente de comunicación ante lo sagrado o lo transcendente, con el mundo físico, con todo lo que acontece en él. Ocurre que en Venezuela no hay un patrón que determine unas directrices de este fenómeno, dado que la estructura religiosa presente en el país, da a luz valores éticos y religiosos que conjugan en sí los principios evangélicos católicos, con la magia afrocubana y con el animismo amerindio.

Por tanto, no resulta extraño que, a través de las expresiones de religiosidad popular en Venezuela -en concreto con la práctica de la santería-, el fiel busca soluciones inmediatas, respuestas contiguas de la divinidad a todos sus problemas, ya sean de corte material, ya sean de índole espiritual.

\section{La pastoral como campo para la evangelización y el dialogo}

La Venezuela del siglo XXI atraviesa por cambios muy notorios, en sus diferentes sectores. Ya sea en lo político y social, ya sea en lo cultural y económico, así como también en la religioso, estos cambios exigen de cada una de las mencionadas instituciones, una reestructuración en la reflexión y hacer en el país Bolivariano, al momento de estudiar el comportamiento de los venezolanos.

La Iglesia católica, ante la declaración constitucional de 1999 que ratifica el estado laical del país, se ve en la necesidad de convertirse en "profeta", esto es, generar diálogos con otras religiones que hacen vida en Venezuela, además de 
denunciar las injusticias contra los más débiles. A pesar de esto, el 71\% (aproximadamente) de la población total, confiesan ser cristianos católicos, de entre los cuales se cuentan un significativo número, el 17\% para mayor detalle, quienes viven su fe católica fusionadas con la de procedencia africana, como por ejemplo la santería, que como ya se ha dicho en la última década ha alcanzado un mayor nivel en el escalafón de prácticas religiosas en este país.

Por tanto, urge para la Iglesia católica la imperiosa necesidad de crear los espacios debidos para la atención de estos católicos-santeros, en una ambiente de dialogo y de evangelización, sin que esto implique que deba renunciar a sus principios evangélicos, pero tampoco un dialogo con el fin de "exterminar" o vetar las prácticas de la santería, que en definitiva, en ellas se encuentra algo de la semilla del Verbo. Este espacio, por supuesto, es posible desde una reflexión pastoral, pero no una pastoral entendida únicamente como "cura de almas" donde el único ministro es el sacerdote, que administra sacramentos, sino, una pastoral que desde un análisis que se haga a la realidad de la comunidad de fieles venezolana, de una manera lúcida y asistida por los aportes que actualmente puede brindar la ciencia, actúe conforme a los resultados que queden de esta evaluación, con el único propósito de buscar "el crecimiento de las personas y de la comunidad como signos del Reino". (Van Den Bosch, 1997. p. 84).

Es evidente que en esto el Concilio Vaticano II, da un paso más allá de lo que hasta entonces los manuales de teología definieron como pastoral. Si bien es cierto, que la pastoral se presentaba como un campo de dialogo y actuación de la Iglesia en el mundo, en concreto con las ciencias humanas, la reflexión de Concilio añade a esta y amplía el espectro de compresión incluyendo, el ecumenismo, el dialogo interreligioso y la misión. A esto hacía referencia, Ramiro Pellitero en su artículo: Itinerario y estatuto de una Teología de la acción social, que publicó la revista Scripta Theologica "El Vaticano II supuso una maduración y replanteamiento de las relaciones entre la Iglesia y el mundo, entre la fe y la cultura, y propició una dinámica teológica en la comprensión de las tareas de la Iglesia y de los cristianos en ella, para responder mejor a las exigencias de lo que luego se llamará "nueva evangelización".(Pellitero, 2000. p. 436). En Cuba, por ejemplo se han llevado a cabo un par de talleres para la evangelización de estos hermanos, contando con el apoyo de varios Obispos del Caribe, quienes han estado interesados al mismo tiempo preocupados en llevar a todos la evangelización.

Cabe aclarar aquí, que evangelización no significa "imponer" como ocurriera en otrora cuando los españoles imponían el catolicismo, sino una evangelización que siga la propuesta de Juan Pablo II, basada en el respeto y en la disposición de dejarnos enseñar por otros creyentes, puesto que ellos también hay destellos 
de verdad y como decía Santo Tomás de Aquino "la verdad, dígala quien la diga, viene del Espíritu Santo". No se trata de caer en un estado de relativismo y aceptar todo, sino de hacer un proceso de discernimiento entre lo que contradice la fe cristiana y lo simplemente cultural, de tal modo, que lo segundo se presente como una vía de diálogo, entre los santeros y los católicos.

El objetivo principal de la pastoral ha de ser, subsanar la deficiente evangelización que dio paso al sincretismo afro-cristiano, pero esta tarea necesita su tiempo. Se necesita preparar a los líderes pastorales y por supuesto, a la feligresía venezolana en general, en tolerancia, respeto y capacidad de dialogo con los santeros. Sin embargo, son diversos los espacios pastorales desde los que se puede ir avanzando, según indica Raúl Rodríguez en su libro sobre el sincretismo cubano, que si bien es cierto, fueron reflexiones hechas desde la Iglesia cubana y para la Iglesia Cubana, no dejan de tener sus aportes para la Iglesia en Venezuela, donde se comienza a extender la santería afrocubana. El primer espacio que el autor acota es la liturgia, que se ha de inculturizar y desde la parroquias brindar un espacio celebrativo para los grupos afrocubanos. Otro espacio, sería las misas de difuntos, tan solitas por los santeros por su culto a los muertos, se puede ver como en parroquias de Caracas, por mencionar un caso, son enormes listas de difuntos por los que piden se ore en las misas, se podría aprovechar este espacio para la predicación y para la catequesis. También se presenta como un espacio los bautismos, que si bien es cierto, la motivación inicial a pedir el bautismo, no es cristiana, se podría aprovechar el espacio para hacer una buena mistagogia.

Los sacramentales, son otro espacio pastoral, sobre todo el día de la Pascua es cuando más acuden a la celebración católica por la bendición del agua y del fuego. Por otro lado los rosarios deben estar bendecidos por un sacerdote, si bien es cierto que su uso es para ser amuletos, también aprovechar para acercarlos al evangelio en estos espacios, así como también en los Santuarios donde asisten, sobre todo en las celebraciones de algún santo o una fiesta del Señor o de la Virgen y que sea identificados por ellos, con alguno de los "orichas". Otro espacio, y quizás el más complicado, advierte el autor, es aceptarlos a la comunión. En este espacio es donde más se vulnera las sensibilidades de los fieles católicos, al saber que un santero está comulgando, sin embargo, la invitación es evitar rechazar a estos hermanos.

\section{Conclusiones}

Partimos del proceso de colonización, como el suceso detonante en las mezclas culturales y religiosas en América Latina. Especialmente, hacemos referencia a 
Cuba, que sirvió de casa para recibir a numerosas comunidades de esclavos traídos de África, en los barcos españoles.

Vimos que con estos esclavos negros llegaron sus religiones y sus prácticas ancestrales, que les dieron fortaleza y esperanzas, ante las situaciones de opresión y tiranía, propiciada por los colonos. Nos asomamos muy, muy brevemente a como los africanos fueron asociando a sus "orichas" con los santos de la Iglesia Católica, para detenernos un momento en la historia y repasar los hechos en los que fue originando el sincretismo religioso entre lo afro, lo amerindio y lo cristiano.

También ofrecimos un panorama de las concepciones míticas de los africanos, así como también un elenco detallado de sus orichas, sus atributos divinos y sus similitudes con los santos católicos, para poder explicar mejor como se fue gestando la santería, de la que hemos dicho que es una manera de catolicismo popular o religiosidad popular. Ofrecimos, además una definición básica, elemental que ha querido presentar lo más esencial y característico de la santería afrocubana que adquiere un nuevo matiz en Venezuela al matizarse con el culto indígena a María Lionza.

Hicimos un recorrido por los documentos del Magisterio de la Iglesia Católica, en los cuales encontramos un gran bitácora, sobre cómo ha de ser las relaciones entre los miembros de la Iglesia y los hermanos que practican la religiosidad popular bajo la denominación de santería, para concluir que es posible atender a estos hermanos y evangelizarlos de nuevo, con una pastoral que analice la situación y partiendo de este diagnóstico, genere espacios de dialogo, de culto y de catequesis, que orienten a estos hermanos a vivir su fe centrada en Jesucristo.

Continuamos presentando un bosquejo, en el que se exponen los espacios y algunas sugerencias pastorales que se pueden aprovechar para la evangelización. Partimos del hecho que entre los pueblos venezolanos se ha dado una deficiente evangelización, se necesita emprender de nuevo esta campaña misionera.

Advertimos además, sobre la fuerte insistencia que hace a los católicos el Vaticano II, y más fuerte aún se nota esta insistencia en Juan Pablo II y los obispos latinoamericanos, a acercarse con respeto y con espíritu ecuménico, a estos hermanos de prácticas religiosas populares.

Finalizamos esta investigación, insistiendo en un trabajo pastoral que ayude a los hermanos de las prácticas sincréticas de la santería, a iniciar un camino de discernimiento y se geste en ellos el deseo de participar plenamente en una comunidad y profese su fe cristiana de una manera más explícita. 


\section{Siglas:}

CP Conferencia de Puebla.

CA Conferencia de Aparecida.

DC Documento Medellín.

DI Discurso del Papa Juan Pablo II a los obispos de Cuba en visita «ad limina apostolorum»

NA Nostra Aetate.

ns Numerales

\section{Referencias}

Bolívar, N. (1997). El legado africano en Cuba. Papers, (52), pp. 155-166. Camargo, J. C. (2012), Los Hijos de la luz. En: https://www.facebook.com/santeria2012/ posts/467103760018106. Recuperado: 11 de agosto de 2014.

Consejo Episcopal Latinoamericano (CELAM). (2007) Documentos conclusivos de la $V$ Conferencia del Episcopado Latinoamericano y del Caribe. Aparecida: San Pablo.

Fernández, T. (1994). Hablen paleros y santeros. Madrid: Ciencias Sociales- La Habana.

Izard, G. (1999). Religiosidad venezolana. Cuadernos (21). Caracas: África América Latina.

Muñoz J. (2006). En: http://cubayoruba.blogspot.com/2006/12/religion-yoruba.html. Recuperado: 6 de agosto de 2014.

Navarro, J. (2002). Religiones del Mundo. España: Grupo Océano.

Pérez, C. (Obá Ecún). (1989). Santería: la religión Lucumí o Yoruba. Caracas: Panapo.

Pollak-eltz, A. (1984). Santería en Venezuela. Caracas: Montalbán.

Pellitero, R. (2000). Itinerario y estatuto de una Teología de la acción social. Navarra: Scripta Theologica, 32 (2), 433-470.

Rodríguez, R. (2012). Sincretismo cubano, Santeros, ñáñigos, paleros y espiritistas. Bogotá: San Pablo.

Saldivar, J. (2010). Iború, Iboya, Ibochiché: the rituals of Santeria, symbolic acts and performance, Encrucijada Americana, 2. En: http://www.academia.edu/7800219/Revista_Encrucijada_Americana. Recuperado: 6 de agosto de 2014.

Wilkinson, P. (2008). Religiones. Buenos Aires: El Ateneo. 


\section{Otras páginas Web consultadas:}

http://cubayoruba.blogspot.com/2006/12/los-orishas.html.

http://www.vatican.va/archive/hist_councils/ii_vatican_council/documents/ vat-ii_decl_19651028_nostra-aetate_sp.html

http://www.celam.org/doc_conferencias/Documento_Conclusivo_Puebla.pdf 